\title{
Can we use an early warning system for tricuspid regurgitation?
}

\author{
Vinay Badhwar, $\mathrm{MD},{ }^{\mathrm{a}}$ and Steven F. Bolling, $\mathrm{MD}^{\mathrm{b}}$
}

See related article on pages 323-30.

In this issue of the Journal, Nemoto and colleagues ${ }^{1}$ have elegantly analyzed data from their institutional imaging database to estimate possible anatomic predictors of the progression of tricuspid regurgitation (TR). By reviewing 622 patients without known tricuspid pathology undergoing both computed tomographic angiography and conventional 2-dimensional echocardiography, they determined that the progression from none or trivial to moderate or severe TR was heralded by structural changes that included the following: circularization of the normal 3-dimensional tricuspid annulus, atrial enlargement (right and left), and finally, annular enlargement. Nemoto and colleagues ${ }^{1}$ further note that these changes may precede the occurrence of TR.

Until recently, the performance of primary or concomitant tricuspid valve repair (TVR) for anything less than severe TR was considered to be either irrelevant or too high risk. In fact, the 2006 American College of Cardiology and American Heart Association guidelines for valvular heart disease went so far as to make TVR in the setting of mild primary TR or asymptomatic secondary TR a class III recommendation. ${ }^{2}$ Evidence has emerged, however, that TVR performance at the time of mitral operation for severe and less-than-severe TR may have a long-term impact on outcome improvement. ${ }^{3-7}$ The 2014 American College of Cardiology and American Heart Association guideline update now supports TVR in the setting of mild, moderate, or greater functional TR at the time of leftsided valve surgery with either tricuspid annular dilation or previous evidence of right-sided heart failure as a class II indication. ${ }^{8}$ This joins the more aggressive approach to functional TR established by the European Society of Cardiology, in which concomitant TVR for moderate TR, including when the tricuspid annulus is greater than $40 \mathrm{~mm}$, is considered a class IIa recommendation. ${ }^{9}$

\footnotetext{
From the a Department of Cardiothoracic Surgery, University of Pittsburgh, Pittsburgh, Pa; and the ${ }^{b}$ Department of Cardiac Surgery, University of Michigan, Ann Arbor, Mich.

Disclosures: Authors have nothing to disclose with regard to commercial support.

Received for publication May 20, 2015; accepted for publication May 21, 2015; available ahead of print June 24, 2015.

Address for reprints: Vinay Badhwar, MD, Department of Cardiothoracic Surgery, University of Pittsburgh, 200 Lothrop St, C-724, Pittsburgh, PA 15213 (E-mail: badhwarv@upmc.edu).

J Thorac Cardiovasc Surg 2015;150:331-2

$0022-5223 / \$ 36.00$

Copyright (c) 2015 by The American Association for Thoracic Surgery http://dx.doi.org/10.1016/j.jtcvs.2015.05.056
}

Right ventricular dysfunction is known to be a late sequela of volume overload and significant TR. This finding is supported by the study of Nemoto and colleagues, ${ }^{1}$ yet they were careful to note that their cardiac structural observations implied asso-

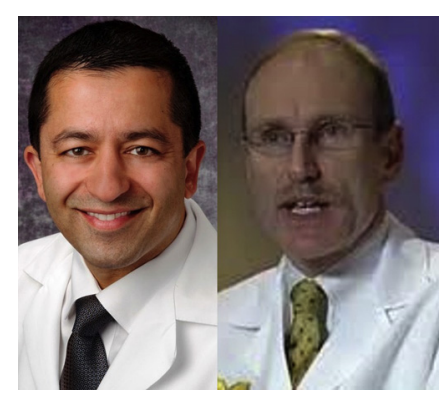
ciation rather than causality with TR progression. Nevertheless, the discovery that early pathoanatomic signs might herald the occurrence or progression of TR appears to imply a structural basis for a more aggressive approach to concomitant TVR. Moreover, this study was a snapshot of a population without known cardiac pathology and thus does not substitute for much-needed robust longitudinal clinical investigation on the natural history of TR, with or without pathoanatomic predictors. One cannot help but make the comparison to the natural history of primary mitral regurgitation. Yet, although we have known the pathoanatomic predictors and natural history of mitral regurgitation since the late 1990s, only recently has asymptomatic severe mitral regurgitation become a widely accepted target for guideline-directed surgical therapy. ${ }^{8,10}$ So even if we were aware of proven early structural predictors of TR, how long would it take asymptomatic or mild TR to reach wide acceptance as a surgical target?

Before we use structural predictors to guide prophylactic TVR before TR exists, we need to become more comfortable with performing concomitant TVR. The first hurdle is addressing the concept of adding surgical risk. In a recent analysis of the Society of Thoracic Surgeons Adult Cardiac Surgery Database, it was determined that the addition of a concomitant TVR to an isolated mitral operation can be performed with no increase in risk-adjusted mortality (odds ratio 0.99) but a slight increase in risk-adjusted major morbidity (odds ratio, 1.36 ). ${ }^{11}$ This study examined 88,473 mitral valve operations performed between 2011 and 2014 to determine that a TVR was concomitantly performed in only $14.3 \%(\mathrm{n}=12,623)$. When patients were subdivided by degree of TR, the rate of TVR when the TR grade was severe was $75.6 \%(5654 / 7482)$, but this dropped to $30.6 \%(4661 / 15,222)$ when the TR was moderate. Importantly, only $3.5 \%(2308 / 65,769)$ underwent TVR when the TR was categorized as none or mild. In contemporary practice, the majority of all North American centers perform concomitant TVR in less than a quarter of their mitral operations. ${ }^{11}$ 
Clearly, clinical validation is required to determine the impact of structural pathoanatomic predictors of TR progression beyond just annular size. With their work, Nemoto and colleagues ${ }^{1}$ have helped inform the study design of future investigations. If corroborated, perhaps some of these early warning signs may find their way into the surgical decision making as to when to perform TVR in nonsevere TR. For now, surgeons need first to become more comfortable with the concept that performing concomitant TVR for nonsevere TR may confer longitudinal benefit ${ }^{6-9}$ without added mortality ${ }^{11}$ before suggesting intervention on the basis of atrial size and annular geometry without annular enlargement or even TR.

\section{References}

1. Nemoto N, Lesser JR, Pedersen WR, Sorajja P, Spinner E, Garberich RF, et al. Pathogenic structural heart changes in early tricuspid regurgitation. J Thorac Cardiovasc Surg. 2015;150:323-30.

2. Bonow RO, Carabello BA, Chatterjee K, de Leon AC Jr, Faxon DP, Freed MD, et al; 2006 Writing Committee Members; American College of Cardiology/ American Heart Association Task Force. 2008 Focused update incorporated into the ACC/AHA 2006 guidelines for the management of patients with valvular heart disease: a report of the American College of Cardiology/American Heart Association Task Force on Practice Guidelines (Writing Committee to Revise the 1998 Guidelines for the Management of Patients With Valvular Heart Disease). Endorsed by the Society of Cardiovascular Anesthesiologists, Society for Cardiovascular Angiography and Interventions, and Society of Thoracic Surgeons. Circulation. 2008;118:e523-661.
3. Dreyfus GD, Corbi PJ, Chan KM, Bahrami T. Secondary tricuspid regurgitation or dilatation: which should be the criteria for surgical repair? Ann Thorac Surg. 2005; 79:127-32.

4. Desai RR, Vargas Abello LM, Klein AL, Marwick TH, Krasuski RA, Ye Y, et al. Tricuspid regurgitation and right ventricular function after mitral valve surgery with or without concomitant tricuspid valve procedure. J Thorac Cardiovasc Surg. 2013;146:1126-32.e10.

5. Goldstone AB, Howard JL, Cohen JE, MacArthur JW Jr, Atluri P, Kirkpatrick JN, et al. Natural history of coexistent tricuspid regurgitation in patients with degenerative mitral valve disease: implications for future guidelines. $J$ Thorac Cardiovasc Surg. 2014;148:2802-9.

6. Benedetto U, Melina G, Angeloni E, Refice S, Roscitano A, Comito C, et al. Prophylactic tricuspid annuloplasty in patients with dilated tricuspid annulus undergoing mitral valve surgery. J Thorac Cardiovasc Surg. 2012;143:632-8.

7. Chikwe J, Itagaki S, Anyanwu A, Adams DH. Impact of concomitant tricuspid annuloplasty on tricuspid regurgitation, right ventricular function, and pulmonary artery hypertension after repair of mitral valve prolapse. J Am Coll Cardiol. 2015;65:1931-8.

8. Nishimura RA, Otto CM, Bonow RO, Carabello BA, Erwin JP III, Guyton RA, et al. 2014 AHA/ACC guideline for the management of patients with valvular heart disease: executive summary: a report of the American College of Cardiology/American Heart Association Task Force on Practice Guidelines. J Thorac Cardiovasc Surg. 2014;148:e1-132.

9. Vahanian A, Baumgartner H, Bax J, Butchart E, Dion R, Filippatos G, et al. Guidelines on the management of valvular heart disease: The Task Force on the Management of Valvular Heart Disease of the European Society of Cardiology. Eur Heart J. 2007;28:230-68.

10. Suri RM, Vanoverschelde JL, Grigioni F, Schaff HV, Tribouilloy C, Avierinos JF, et al. Association between early surgical intervention vs watchful waiting and outcomes for mitral regurgitation due to flail mitral valve leaflets. JAMA. 2013;310: 609-16.

11. Badhwar V, He M, Rankin JS, Jacobs JP, Gammie JS, Furnary AP, et al. Performing concomitant tricuspid valve repair at the time of primary mitral operation is not associated with increased mortality. J Thorac Cardiovasc Surg. 2015. In press. 